\title{
Venezuelan researchers call for international help
}

\section{Political conflict is endangering human life, scientific endeavour and a rich environment.}

Sir — Venezuela has entered 2003

deadlocked in a dangerous political confrontation and a general strike that has lasted two months so far. Scientific endeavour, like everything else, has been seriously disrupted by the crisis, partly because many researchers and postgraduate students support the strike, but more imminently because salaries, project funding and basic services such as gas, electricity, liquid nitrogen, transport and the Internet are no longer reliable. We find ourselves in a chaotic environment where it is next to impossible to fulfil national and international research commitments.

One notorious casualty is Intevep the R\&D branch of the national oil company PDVSA — which has practically come to a standstill and so is now earmarked for 'major restructuring' by the Ministry of Energy and Mining.

Our Venezuelan Institute for Scientific
Research (IVIC) and the national research universities have been prostrated by financial cuts starting last year. We hear many threats of government intervention.

The Association of Investigators of IVIC (AsoInIVIC) has been hosting assemblies and electronic debates in the past two months. We have sent out press releases in which we deplore the recent spread of politically motivated violence, including the killing of unarmed demonstrators by paramilitary groups.

A consultative referendum was legally scheduled for early February, but has been suspended by the Supreme Tribunal. A table of negotiation and agreements has been set up by the Organization of American States, chaired by its Secretary General, Dr César Gaviria: we have urged the 20 negotiators to support the consultative referendum.

We have also issued warnings against misuse of PDVSA's equipment and infrastructure by uncertified personnel because accidents involving human lives and the environment have already occurred - for example, 79 reported oil spills on Lake Maracaibo since the conflict began.

We at AsoInIVIC are struggling to preserve Venezuela's science and its natural environment, which is rich in biodiversity. We ask the scientific community to help by exerting pressure, for example through learned societies and UNESCO; by raising funds to help us meet commitments abroad; by backing local groups, through environment agencies, in denouncing the ecological disasters; and by remaining patient while we return to normality. C. Mendoza (president), J. A. Urbina (secretary general)

Association of Investigators of IVIC, Venezuelan Institute for Scientific Research, PO Box 21827, Caracas 1020A, Venezuela

\section{No reduction in risk of a massive asteroid impact}

Sir - An important, technically valid analysis of meteoric fireball data (P. Brown et al., Nature 420, 294; 2002) has been transformed into media stories asserting (falsely) that the threat from dangerous asteroids is less than once thought. Nature joined the media hyperbole with words on its cover about "reassessing the hazard", although the data published by Brown et al. have nothing to do with the hazard.

Brown et al. studied satellite and infrasound data over an 8.5-year period pertaining to impacts of meteoroids $1-10$ metres in diameter. Except for the few per cent that are strong nickel-iron, such objects burn up harmlessly high in the Earth's atmosphere. Thus they constitute no direct danger. Only objects perhaps 1,000 times more massive than the largest studied by Brown et al. actually reach the ground with much cosmic velocity intact.

Yet many of the media reports about the paper asserted that this implies that the frequency of dangerous near-Earth asteroid (NEA) impacts is decreased, and therefore that the hazard has also declined significantly. In just one of many examples, the Los Angeles Times editorialized on 30 November 2002 that "if Nature is to be believed" then asteroids capable of causing catastrophic damage "can recede from the worry list".

But the danger from NEAs is not less than once thought. Nature, in its own press release, mentioned the extrapolation by Brown et al. of their data to objects tens of metres in size, like the small NEA that caused the roughly 10 megaton 'Tunguska' explosion over Siberia in 1908. But the lower, once-a-millennium estimate for Tunguskas derives from telescopic Spaceguard Survey data reported during the past two years (see, for example, D. Rabinowitz et al., Nature 403, 165-166; 2000), not from the study by Brown et al. of much smaller objects. And even Tunguskas contribute very little to the hazard, which is dominated by rare impacts of NEAs several thousand times more massive than Tunguska (with diameters $1-3 \mathrm{~km}$ ).

The estimated frequency of such larger NEAs (and hence of the total impact hazard) is not changed by the work that Brown et al. have done. Indeed, data analyses during the past year suggest that NEAs of civilization-threatening sizes may be more numerous than previous estimates by tens of per cent.

For such low-probability events as NEA impacts, the important issue is not the statistical frequency but the determination of whether there is (or is not) an asteroid that will collide with Earth in the next few decades. That is the purpose of the Spaceguard Survey - to find these NEAs one at a time, and determine from their orbits whether or not they pose a danger in the near future.

Clark R. Chapman ${ }^{\star}$, David Morrison $\dagger$

*Southwest Research Institute, 1050 Walnut Street, Boulder, Colorado 80302, USA

$\dagger$ NASA Ames Research Center, Moffet Field, California 94035, USA
Was visionary Seaborg from far-sighted stock?

Sir - In a letter that I received inviting me to become a 'Consulting Fellow' for the World Innovation Foundation, I discovered (amid considerable other hyperbole) that some honours are so great as to defy accurate description.

Glenn Seaborg was founding president of the World Innovation Foundation, so it was only fitting that the letter should try to capture the significance of his achievements and his stature as a person: "As one of the twentieth century's greatest scientists and the only person ever in the history of the world to be named after one of the Universe's Elements (Element 106 Seaborgium) whilst still living, [Nobel Laureate Glenn Theodore Seaborg] has left a huge scientific legacy for us all."

Glenn's parents must have been unusually prescient. Fortunately, the website (www.ineed.easynet.co.uk/wif/ mainmembers.html) has it right, so only those of us honoured with an invitation letter might have momentarily mused over the order of events.

\section{A. Richard Palmer}

Department of Biological Sciences,

University of Alberta, Edmonton,

Alberta T6G 2E9, Canada

\section{correspondence}

Contributions to Correspondence may be submitted to corres@nature.com. They should be no longer than 500 words, and ideally shorter. Published contributions are edited for length. 